\title{
OS DESAFIOS DA TUTELA ESPECÍFICA EM RELAÇÃO AOS NOVOS DIREITOS E À RESPONSABILIDADE SOCIAL EMPRESARIAL
}

\section{THE CHALLENGES OF SPECIFIC TUTELAGE IN RESPECT OF NEW RIGHTS AND THE SOCIAL RESPONSIBILITY BUSINESS}

\author{
Leandro Cioffi" \\ Yvete Flávio da Costa**
}

\begin{abstract}
Resumo: Inicia-se o presente ensaio introduzindo o problema em questão, posteriormente faz-se uma breve análise sobre os elementos das tutelas antecipada e específica e suas respectivas diferenças técnico-instrumentais. Em seguida, tem a abordagem das dificuldades de identificação dos direitos obrigacionais de acordo com a realidade contemporânea e os conseqüentes prejuízos para a concessão das tutelas urgentes, e por último, o que isso reflete quando a matéria for relativa às obrigações pertencentes ao universo da responsabilidade social empresarial.
\end{abstract}

Palavras-chave: Tutela específica. Tutela urgente. Direitos obrigacionais. Novos direitos. Responsabilidade social empresarial.

\begin{abstract}
The present essay starts with an introduction to the issue under discussion and proceeds with a brief analysis of the elements constituting specific and early tutelage and their technical-instrumental differences. After that, the text approaches the difficulties to identify the rights obligations according to the contemporary reality and the consequent losses for the granting of urgent tutelages. Finally, it deals with the impacts when the matter relates to obligations belonging to the universe of social responsibility business.
\end{abstract}

Keywords: Specific tutelage. Urgent tutelage. Rights obligations. New rights. Social responsibility business.

Mestrando em Direito pela UNESP de Franca. Bolsista do Programa Demanda Social junto à Coordenação de Aperfeiçoamento de Pessoal de Nível Superior - CAPES.

Pós-Doutorado em Direito pela Universidade de Coimbra. Mestre e Doutora em Direito pela PUC/SP. Professora de Direito Processual Civil da UNESP de Franca. 


\section{INTRODUÇÃO}

O direito processual civil dispõe de mecanismos jurídico-normativos visando a efetividade da tutela jurisdicional, principalmente quando se trata de decisões antecipatórias em caráter liminar ou mediante justificação prévia relacionadas ao cumprimento de obrigações de fazer e não fazer em face das relações sociais brasileiras.

Porém, demonstram-se algumas problemáticas na devida concessão das tutelas específicas quando não se têm facilmente evidenciadas essas relações obrigacionais em face da realidade contemporânea calcada na dinâmica social e econômica, das quais se criam novas formas de prática de atos na vida civil, onde nem sempre o direito privado positivo é capaz de acompanhá-los e discipliná-los.

Assim, mesmo que as tutelas específicas sejam estudadas no direito processual, o direito material ganha atenção especial em questão, levando em conta a real e necessária aproximação dessas duas espécies de direito, visando coerência e efetividade nas tutelas pretendidas. Compreender o direito material passa a ser algo fundamental para a análise instrumental da tutela específica.

No presente trabalho, não se tem o fim de analisar exaustivamente o direito obrigacional brasileiro, mas apenas expor elementos significativos para introduzir uma proposta de reflexão crítica a respeito da concessão das tutelas específicas relativas aos objetos de obrigações de fazer, não fazer ou a prática de atos ilícitos a serem inibidos.

Além disso, visa-se também introduzir reflexões acerca da efetividade da tutela específica numa nova realidade que ainda o direito material não desenvolveu sistematicamente com suficiência, que é o estudo da responsabilidade social empresarial pertencente ao universo dos chamados "Novos Direitos", mas com a sua especificidade técnica da vida empresarial. Assim, far-se-á uma abordagem relativa à problemática das obrigações neste campo material e quais os problemas a serem enfrentados processualmente no estudo das tutelas específicas, procurando saber se esse instrumento está sendo suficiente para tanto.

\section{A INSTRUMENTALIDADE NA FUNÇÃO DE TUTELA URGENTE}

É possível afirmar que no Brasil a primeira demonstração de tutela específica se deu por meio da Lei da Ação Civil Pública (7347/85), que dispõe em seu artigo 11 que em ações dessa natureza as quais tiverem por objeto a obrigação de fazer ou não fazer, o juiz determinará a sua aplicação ou a cessação da atividade nociva, sob pena das sanções legais nela previstas. 
Os desafios da tutela específica em relação aos novos direitos e à responsabilidade social...

Em 1990, o Código de Defesa do Consumidor trouxe em seu teor, na redação de seu artigo 84, que as ações que tiverem por objeto o cumprimento de obrigação de fazer ou não fazer, o juiz concederá a tutela específica da obrigação ou determinará providências que assegurem o resultado prático equivalente ao do adimplemento, sob pena das sanções legais nela previstas.

Em 1994, este texto foi igualmente inserido no teor do Código de Processo Civil por meio de sua pequena reforma ao transformar o seu artigo $461 \mathrm{em}$ dispositivo de tutela específica ao repetir literalmente a redação do CDC supramencionada. Além disso, trouxe ainda no processo civil por meio da nova redação dada ao artigo 273 do CPC, passando a dizer que o juiz concederá, total ou parcialmente, a antecipação dos efeitos da tutela na inicial, desde que, existindo prova inequívoca da verossimilhança da alegação e do fundado receio de dano irreparável ou de difícil reparação, ou então que fique caracterizado o abuso de direito de defesa ou o manifesto propósito protelatório do réu. Além disso, o seu parágrafo 7a prevê que se o autor, a título de antecipação de tutela, requerer uma providência de natureza cautelar, o juiz poderá deferi-la em caráter incidental desde que haja os pressupostos para tanto, isto é, a generalidade do fumus boni iuris e do periculum in mora.

O que há em comum entre a tutela antecipada e a específica é que ambas possuem a natureza jurídica mandamental e que se efetiva mediante a execução lato sensu, conforme a expressão de Nelson Nery Jr. e Rosa Maria Andrade Nery (2001), isto é, uma dicotomia denominada por processo de conhecimentoexecução (WATANABE, 2000).

Segundo Pontes de Miranda, ação mandamental "é aquela que tem por fito preponderante que alguma pessoa atenda, imediatamente, ao que o juízo manda" (1998, p. 23) e esse mandamento poderia se dar no ato da sentença, mas vislumbra-se que na sistemática das tutelas antecipadas e específicas é possível que se dêem também durante o processo, desde que atendidos alguns requisitos para tanto. Com relação à ação executiva "é aquela pela qual se passa para a esfera jurídica de alguém o que nela devia estar, e não está” (1998, p. 135).

Em se tratando das diferenças entre essas tutelas, reporta-se a pertinente ilustração nas atualizações de José Frederico Marques, onde Vilson Rodrigues Alves ressalta que, em relação à antecipação dos efeitos da tutela, "não há provimento jurisdicional liminar acautelatório, mas provimento decisório antecipatório do provimento sentencial, com idêntico ou menor teor quanto à matéria fática, com o discrime único da provisoriedade” (2000, p. 27), isto é, a tutela antecipada é a antecipação provisória total ou parcial daquilo que foi 
pretendido na ação de conhecimento e, atendidas as exigências legais para tanto, sua concessão visa evitar a submissão desnecessária do autor a todo o trâmite da demanda, da inicial ao trânsito em julgado, para depois iniciar a fase executória.

Como bem acentua Nelson Nery Jr., fazendo uma comparação teórica com as possibilidades de antecipação dos efeitos da tutela previstos no direito italiano, afirma que, no Brasil, esta garantia processual visou também evitar o abuso do direito de defesa do réu (1996) ensejado nos atos protelatórios a ele garantidos sistematicamente na instrumentalidade do direito processual civil, isto é, evitar que o réu se aproveite dos recursos a ele permitidos pelo direito processual, capazes de se beneficiar indevidamente pelos efeitos da conseqüente morosidade e da fuga sistemática na reparação de danos.

$\mathrm{Na}$ verdade, como bem ressalta Ovídio Batista, em se tratando da inclusão da tutela antecipada no Código Civil, "evitou o legislador aludir à antecipação dos efeitos da sentença de procedência. Mas é evidente que antecipar "os efeitos da tutela pretendida pelo autor” corresponderá sempre a antecipar efeitos da sentença de procedência" (BATISTA, 2000, p. 134). Assim, em termos práticos, a tutela antecipada é uma quase procedência da ação pretendida pelo autor no tocante ao mérito, destacando-se que é uma decisão interlocutória ao invés de uma suposta sentença antecipada.

Porém, para a tutela antecipada há uma exigência e um rigor maior para sua concessão do que para a tutela específica. A tutela antecipada possui uma dimensão maior para sua concessão no tocante ao objeto da ação, criando abrangência maior do que a mera obrigação de fazer ou não fazer e, em contrapartida, seus requisitos para sua concessão são mais rigorosos e exigentes. Já a tutela específica, como o nome já diz, é específica no objeto das obrigações de fazer e não fazer, limitando sua abrangência apenas no aspecto obrigacional, porém, seus requisitos para concessão são menos exigíveis e rigorosos, bastando apenas constatar a referida relação obrigacional. Assim, a tutela específica possui seu caráter de remédio processual mais eficiente do que o da tutela antecipada, e mais adequado para situações de urgência e de emergência, tanto é que sua aplicação se originou na tutela de direitos meta ou transindividuais conforme revelam os teores da Lei de Ação Civil Pública e o Código de Defesa do Consumidor.

Nessa linha de pensamento, tem-se a concordância com as conclusões semelhantes às de Nelson Nery Jr. (1996) quando este relata as seguintes observações a respeito das diferenças instrumentais de tutelas antecipadas com as específicas: 
Os desafios da tutela específica em relação aos novos direitos e à responsabilidade social...

É interessante notar que para o adiantamento da tutela de mérito, na ação condenatória em obrigação de fazer ou não fazer, a lei exige menos do que para a mesma providência na ação de conhecimento tout court (CPC 273). É suficiente a mera probabilidade, isto é a relevância do fundamento da demanda, para a concessão da tutela antecipatória de obrigação de fazer ou não fazer, ao passo que o CPC 273 exige, para as demais antecipações de mérito: a) a prova inequívoca; b) o convencimento do juiz acerca da verossimilhança da alegação; c) ou o periculum in mora (CPC 273 I) ou o abuso do direito de defesa do réu (CPC 273 II). (p. 121).

Por fim, ressalta outra diferença entre essas tutelas, ao afirmar que a tutela específica tem sua semelhança à tutela cautelar, ao passo que a antecipada é totalmente diferente daquela, pois nesta enquanto o objetivo é "adiantar o bem de vida do autor" àquela referida cautelar visa apenas assegurar o resultado útil do processo de conhecimento ou da execução (NERY JR, 1996, p. 122).

Ocorre que, ao trazer a apreciação mista de direito processual e material, conseqüentemente, à luz da dinâmica social e econômica, mesmo havendo uma abrangência menor e menos rigorosa do que a tutela antecipada, a tutela específica cria uma complexidade de grandes dimensões ao tomar conhecimento da identificação de relações obrigacionais à luz da realidade contemporânea, tendo em vista as mudanças de comportamento calcadas nos avanços científicos, tecnológicos, culturais, sociais, econômicos, políticos, etc., onde tal problemática será abordada no item seguinte.

Dando continuidade à análise instrumental da tutela específica, Nelson Nery Jr. (1996) ressalta que ela se trata de uma execução específica da qual possui uma regra mista de direito material e de direito processual, isto é, "ação de conhecimento de execução de obrigação de fazer ou não fazer" (p. 119-120), onde, diferentemente da ação que já tenha o título executivo (no caso de ações de execução), o autor, no mesmo instrumento de ação de conhecimento, requer a condenação do réu ao cumprimento das referidas obrigações. Afinal, aproveitando-se das lições de Luiz Guilherme Marinoni (2000), destaca-se a seguinte observação a respeito:

Como é sabido, a doutrina processual contemporânea tomou consciência de que o processo não pode ser pensado à distância do direito material. Nessa linha a doutrina fala em efetividade do processo e em tutela jurisdicional dos direitos, sempre preocupada com um processo que seja capaz de dar ao autor o resultado que o próprio direito material lhe outorga. (p. 57).

Nessa situação, a vantagem de se ingressar com uma ação de conhecimento pedindo tutela específica, ao invés de ingressar uma ação de execução, é que 
nesta deve se ater exclusivamente ao título executivo que constitui a obrigação de fazer ou não fazer, ao passo que naquela ação pode haver outros pedidos no teor da mesma lide cognitiva e, além disso, quando a obrigação de fazer não está assegurada em título executivo a ação cognitiva provoca uma espécie de cognição sumária para a concessão de uma execução urgente para o caso concreto.

O referido autor faz ainda uma observação técnica que, por meio dos artigos 461 do CPC e 84 do CDC, há uma exceção à regra de que o juiz deve se ater congruentemente ao pedido da ação, pois estes dispositivos legais permitem ao aplicador ordenar o cumprimento de determinada obrigação de fazer ou não fazer, ou determinar medidas necessárias para o seu cumprimento ou o resultado prático equivalente ao do adimplemento (MARINONI; ARENHART, 2007).

Dadas essas diferenças técnico-instrumentais entre tutelas antecipadas e específicas, nota-se evidentemente que se descarta qualquer equívoco no tocante a uma suposta ilustração de que uma tutela antecipada pode ser gênero devido sua maior abrangência e a específica como espécie daquela. Porém, é comum na prática forense a generalização de pedidos e concessões de tutelas antecipadas, tendo por objeto da ação as obrigações de fazer e não fazer. Se essas tutelas realmente preencherem as exigências da redação constante do artigo 273 elas serão vantajosas, pois descarta-se eventuais abusos de direito do réu, agora, se a concessão se der como medida cautelar embasada no parágrafo sétimo do referido artigo, gera prejuízos a uma das partes envolvidas na lide, principalmente o réu eventualmente, causando assim uma espécie similar a um abuso de direito do autor.

Para a referida medida cautelar, tem-se por requisitos para sua concessão apenas o fumus boni iuris e o periculum in mora. Considerando que o que se tem às vezes é apenas uma "fumaça do bom direito" e não um direito concreto em si, a concessão de uma tutela dessa natureza referente a um objeto caracterizado por obrigação de fazer e não fazer leva a uma tutela precipitada de algo que nem sempre está concreta a sua composição material mais precisa de uma obrigação. Assim sendo, a concessão de uma tutela com base na fumaça de uma obrigação leva a um abuso de direito do autor em face do réu, podendo gerar até manifesto arbitrário do Estado-juiz, pois para o instituto material das obrigações, estas estão mais próximas da liquidez e da certeza do que outros institutos jurídicos, possibilitando que haja maior atenção, definição e concretude da constatação obrigacional do que uma mera fumaça jurídica. 
Os desafios da tutela específica em relação aos novos direitos e à responsabilidade social...

A tutela específica tem o seu caráter peculiar para evidenciar o direito obrigacional e a sua devida aplicação tutelar numa lide, onde sua interpretação não pode jamais ficar presa aos requisitos instrumentais da tutela antecipada e nem soltos às medidas cautelares, sob pena de ocorrer despachos ou decisões injustas e prejudiciais a alguma das partes envolvidas na lide. Assim, a tutela específica tem o caráter de trazer para o processo de conhecimento a oportunidade de haver uma interpretação inicial de direito material na composição do despacho de maneira mais precisa e não meramente instrumental, como se faz na tutela antecipada ou carente de maior segurança e certeza, como nas medidas cautelares, isto é, o aplicador deverá desenvolver um conhecimento mais peculiar e cuidadoso de direito material ao examinar um pedido instrumental tutelar referente às obrigações de fazer e não fazer.

\section{PROBLEMAS DE IDENTIFICAÇÃO DO DIREITO MATERIAL NA TUTELA ESPECÍFICA}

Desde já, é importante ressaltar a expressiva observação de Cândido Rangel Dinamarco a respeito das tutelas específicas ao afirmar que "a tutela jurisdicional efetiva não está nas sentenças, mas nos resultados práticos que elas venham efetivamente a produzir na vida das pessoas" (2002a, p. 600) e pelo seu caráter de medida executiva lato sensu visa, com base na doutrina germânica, "eliminar as crises de adimplemento" (2002b, p. 245).

Observa ainda que, segundo Marinoni e Arenhart (2007), com o passar do tempo, e com o surgimento de novos direitos, foi necessário que no processo civil houvesse novas técnicas para a tutela dos direitos, permitindo que surgissem as sentenças mandametais e executivas, inseridas na inteligência do artigo 84 do Código de Defesa do Consumidor e posteriormente no artigo 461 do Código de Processo Civil.

[...] a necessidade de pensar o processo na perspectiva de direito material obriga-nos a raciocinar em termos de tutela dos direitos, o que acaba exigindo uma nova elaboração dogmática, capaz de dar conta dos reais significados dos resultados do processo no plano do direito substancial (MARINONI, 2000, p. 61).

A redação do artigo 84 do Código de Defesa do Consumidor - semelhante à do artigo 461 do Código de Processo Civil em vigor - introduz teoricamente a proteção dos direitos difusos e coletivos, levando em consideração que tal redação está inserida sistematicamente na tutela dos direitos, tanto individuais quanto coletivos, segundo o caput do artigo 81 do referido diploma legal 
dos consumidores. Ocorre que sua sistemática processual apenas traz ao conhecimento prévio a apreciação do direito material obrigacional e assim, traz os problemas de interpretação do aplicador ao identificar juridicamente uma relação obrigacional diversa daquelas desenvolvidas numa perspectiva privatista e contratualista.

O grande desafio da doutrina contemporânea não é o de apenas estudar as novas técnicas de tutela, mas sobretudo o de, a partir das reais e concretas necessidades do direito material, isolar e delinear as tutelas que devem responder de forma adequada a essas necessidades (MARINONI, 2000, p. 62).

Segundo Dinamarco (1996), os referidos artigos têm a "dimensão suficiente para abranger todas as obrigações específicas ocorrentes na vida das pessoas, seja as de origem legal, seja contratual” (p. 151). Marinoni e Arenhart (2007) até falam sobre a tutela, numa de suas maneiras de evitar o ilícito, entendendo este em sendo um ato contrário ao direito, distinguindo-a do inadimplemento das obrigações contratuais.

Ocorre que, a dificuldade em questão está não na previsão instrumental de concessão de uma tutela específica ou inibitória, a fim de mandar e executar uma obrigação de fazer ou não fazer, mas sim na identificação desta obrigação ou de inibição de um ato ilícito.

$\mathrm{Na}$ busca de uma compreensão acerca do instituto do direito obrigacional, entende Orlando Gomes (2000) que esse direito "compreende as relações jurídicas que constituem as mais desenvoltas projeções da autonomia privada na esfera patrimonial" (p. 2). Todavia, entende ainda que "o conceito de obrigação deve ser depurado da intromissão de outras noções jurídicas tecnicamente distintas, tais como as de dever jurídico, sujeição e ônus" (p. 6), pois, para ele, trata-se de noções que não se confundem com obrigações, dando o conceito deste em sendo "um vínculo jurídico em virtude do qual uma pessoa fica adstrita a satisfazer uma prestação em proveito de outra” (p. 9), mas admite a acepção em sentido amplo que se trata de expressões sinônimas no sentido de que "obrigação é espécie do gênero dever, reservando-se o termo para designar o dever correlato a um direito de crédito" (p. 11, grifos nosso).

Segundo Maria Helena Diniz (2006), o dever jurídico "é um comando imposto, pelo direito objetivo, a todas as pessoas para observarem certa conduta, sob pena de receberem uma sanção pelo não-cumprimento do comportamento prescrito pela norma jurídica” (p. 29).

Por fim, aproveita-se neste trabalho a definição de Caio Mário da Silva Pereira (2003) ao dizer que "obrigação é o vínculo jurídico em virtude do qual uma pessoa pode exigir de outra prestação economicamente apreciável” (p. 7). 
Os desafios da tutela específica em relação aos novos direitos e à responsabilidade social...

Como é possível observar, no direito civil brasileiro ainda prevalece raízes conservadoras privatistas no tocante às técnicas normativistas e definições doutrinárias do direito obrigacional.

Assim, quando os processualistas acima ilustrados levam ao entendimento de que a tutela específica engloba tanto obrigações quanto inibição de atos ilícitos, dá-se a impressão de que esta segunda situação também envolve a prática de deveres. Nesse sentido, a técnica do artigo 84 CDC e 461 CPC carece do acréscimo da expressão "deveres" em sua redação, de tal maneira que assim haveria maior coerência com os postulados acima. É bem verdade que no estudo do direito material há ainda as obrigações por atos ilícitos, das quais instituídas por lei sua imposição, segundo, por exemplo, reza no Código Civil, por meio de seu artigo 927, que aquele que por ato ilícito praticar dano a outrem fica obrigado a repará-lo, isto é, responsabilidade civil. Resta saber se para esse efeito a expressão obrigação é utilizada como sinônimo de dever. Talvez essa construção da obrigação por ato ilícito seja a solução do problema para o direito processual, pois, independente da conseqüência da responsabilidade civil ser dever ou obrigação de reparar o dano, de fato o efeito mandamental da tutela específica recairá ao praticante do ato ilícito.

No exame do pedido de tutela específica, o aplicador deverá fazer uma interpretação sobre a existência ou não de uma obrigação de fazer ou não fazer, ou a constatação de algum ato ilícito a ser inibido. Daí, para o seu convencimento acerca do pedido é indispensável que haja uma devida fundamentação fática, jurídica e a produção de provas consistentes da existência de tais obrigações.

Porém, a interpretação do direito obrigacional é propícia estritamente aos atos jurídicos calcados à predominância do pacta sunt servanda na construção de direitos no universo da vida civil que assim se limitava no modelo de sociedade liberal e de autonomia privada, bem como a identificação de possíveis atos ilícitos baseados em leis e normas estatais expressas. Ocorre que essa visão é incompatível com a atual realidade do mundo e da sociedade.

A sociedade está cada vez mais dinâmica no tocante ao comportamento humano e social em face de suas necessidades e possibilidades individuais e transindividuais. Essa dinâmica social é provocada por constantes transformações tecnológicas, ecológicas, meteorológicas, culturais, sociológicas, científicas de maneira geral e principalmente com as imprevistas e desenfreadas mudanças na economia capitalista. Diante disso, é tecnicamente impossível disciplinarem todos os deveres e todas as obrigações por meio de leis, normas e convenções capazes de acompanhar esse complexo dinâmico da sociedade. 
Assim, pela vigente disciplina instrumental da tutela específica, ela pode ser prejudicada pela insuficiência de substratos jurídico-formais para a identificação de uma relação obrigacional atualizada ou alguma nova versão de ato ilícito a ser inibido de acordo com a realidade contemporânea, especialmente em se tratando dos deveres e das obrigações oriundas aos chamados "Novos Direitos."

Com isso, a problemática estará na identificação de uma relação obrigacional ou na de atos ilícitos a serem inibidos à luz dos chamados "Novos Direitos", tendo em vista que estes não decorrem somente da instituição de leis ou de demais normas expressas ou meramente convencionais, mas de fatos desenvolvidos no prisma sociológico capazes de se transformar e de se reconhecer como direitos.

Segundo Norberto Bobbio, esses novos direitos se dão na sustentação de que eles se constituem num fenômeno social, cuja tarefa de estudá-los ficaria a cargo dos sociólogos jurídicos de acordo com um fenômeno que ele denomina por transformação multiplicada dos direitos do homem (1992).

Essa multiplicação (ia dizendo "proliferação") ocorreu de três modos: que aumentou a quantidade de bens considerados merecedores de tutela; b) porque foi estendida a titularidade de alguns direitos típicos a sujeitos diversos do homem; c) porque o próprio homem não é mais considerado como ente genérico, ou homem em abstrato, mas é visto na especificidade ou na concreticidade de suas diversas maneiras de ser em sociedade, como criança, velho, doente, etc. (BOBBIO, 1992, p. 68).

Vale ressaltar ainda a afirmação de que esses novos direitos num prisma transindividual não são direitos novos propriamente ditos, pelo contrário, essa discussão teórica não é recente, levando em consideração que até Francesco Carnelutti (1999) já discorria acerca dessa matéria por meio de sua temática sobre as "lides coletivas" (p. 91-93) e os "processos coletivos" (p. 139-140). O que se tem na verdade são novas discussões jurídicas acerca das novas realidades do mundo e da sociedade, levando em conta também a inquestionável e intensa carga social, econômica, política, ética e cultural contida nos fundamentos que geraram a criação desses novos direitos, sobretudo quando eles foram objetos de debates nos países subdesenvolvidos na década de setenta.

Para aqueles que negam a existência de obrigações sem os moldes expressos em lei, Orlando Gomes (2000) ressalta que inúmeras obrigações, com base nos preceitos contidos na parte geral, foram instituídas sem a subordinação esquemática da lei, limitando-se apenas aos princípios gerais que deixam à 
Os desafios da tutela específica em relação aos novos direitos e à responsabilidade social...

vontade individual imensa margem de provocação de efeitos jurídicos nos mais variados interesses de tutela, bem como o entendimento de que o funcionamento do sistema econômico depende de sua disciplina jurídica e, inclusive seus limites à liberdade, incluindo-se também o estudo das obrigações no prisma do direito público.

Assim, o Estado na função jurisdicional ao conceder ou não a tutela específica, sem a ampla observância jurídica e teórica das obrigações de fazer e não fazer ou de algum ato ilícito a ser inibido acerca dos chamados "Novos Direitos”, por nem sempre haver raízes jurídico-formais para tanto, está sendo injustamente arbitrário em face de alguma das partes envolvidas na lide. No Direito Processual Civil, para a concessão da tutela específica é necessário que se comprove a existência da obrigação de fazer ou não fazer ou ainda a existência de um ato ilícito a ser inibido.

Dessa maneira, deixar de conceder uma tutela específica por não haver a juntada nos autos de documentos formais capazes de comprovar uma relação obrigacional ou de elementos formais comprobatórios de um ato ilícito a ser inibido poderia ser um ato de cerceamento indevido e injusto da devida prestação tutelar jurisdicional em se tratando de deveres e obrigações nascidos sociologicamente, principalmente em se tratando de direitos difusos, coletivos, sociais e humanos e, especialmente, ambientais. Por outro lado, conceder uma tutela específica com base em fundamentos levianos que equivocadamente constroem eventuais relações obrigacionais nos chamados "Novos Direitos" leva a uma uma arbitrariedade na aplicação do direito em decorrência da insegurança jurídica e de construções indevidamente ideológicas do intimo pensamento do aplicador.

Em tom de crítica, mesmo havendo algumas previsões normativas, ainda que tímidas, sobre esses novos direitos, há ainda uma imensa dificuldade para que direitos sejam reconhecidos e aplicados de maneira mais efetiva, sobretudo, na tutela desses direitos, levando a crer que a jurisdição brasileira ainda não está sendo devidamente preparada para lidar com essas novas realidades que motivam a instituição de direitos de ordem meta ou transindividual.

Além disso, nossa epistemologia enfatiza o ensino jurídico no aspecto da norma e o conteúdo desses novos direitos possui uma carga política e ética imensa, levando as razões que motivam a luta por esses novos direitos se refratam ao esbarrar no perfil conservador ao status quo, ocasionando decisões injustas ou até mesmo cerceando direitos materiais por força da ótica formalista predominante. Diante disso, tais dificuldades atingem na tutela específica quando houver a identificação no caso concreto de inadimplemento de uma 
obrigação contratual ou a ilicitude de algum diante da complexidade do mundo contemporâneo. Nesse sentido, a temática ganha maiores contornos ao enfatizar o estudo desses novos direitos centralizados na composição jurídica da responsabilidade social empresarial.

\section{OS DESAFIOS DA TUTELA ESPECÍFICA NO UNIVERSO DA RESPONSABILIDADE SOCIAL EMPRESARIAL}

O mundo, especialmente ocidental, vivencia constantes transformações sociais e, sobretudo, no modelo de Estado, com expressivas tendências de mudanças de Estado de bem-estar social para o neoliberalismo ao longo das últimas décadas, levando em conta inúmeras manifestações de descentralização de ações sociais voltadas neste propósito em substituição à insuficiência do Estado para tanto diante da atual conjuntura, isto é, em se tratando de Brasil, "o movimento de Responsabilidade Social empresarial desenvolve-se gradativamente no país, reivindicando, junto à sociedade, um modelo de regulação social com maior vigor e abrangência do que o veiculado pelo Estado" (SIQUEIRA, 2002, p. 97), manifestando-se por diversas maneiras, inclusive por meio de parcerias com entidades do Terceiro Setor, atestadas por meio dos mais variados indicadores de responsabilidade social e ambiental, tais como os selos e certificações reconhecidos por institutos de referência no cenário social e econômico. Além disso, tais indicadores também estão sendo necessários para as empresas até mesmo em relação às licitações com as administrações públicas diretas e indiretas.

O universo empresarial, de acordo com os ensinamentos das cartilhas de administração de empresas, é dividido em dois, a saber, o ambiente organizacional interno e o externo, também conhecido por stakeholders (KARKOTLI; ARAGÃO, 2004), podendo variar conforme a natureza e a organização do empreendimento. Os stakeholders internos se constituem basicamente por empregados, dirigentes, acionistas, investidores, etc. Já os stakeholdes externos, por consumidores, fornecedores, concorrentes, governos, mídia, sindicatos, instituições financeiras, etc. A partir daí, a prática de ações sociais voltadas ao exercício de bem-estar social podem se manifestar tanto no ambiente organizacional interno quanto externo. Assim, a prática de responsabilidade social não se resume somente em ações filantrópicas ou voluntárias, mas em elementos essenciais para a transformação das empresas do estágio meramente econômico para uma postura de emancipação e cidadania empresarial.

A responsabilidade social empresarial é mais do que um simples ato voluntário, mas também obrigações e deveres de prevenção e reparação de 
Os desafios da tutela específica em relação aos novos direitos e à responsabilidade social...

danos causados ou a causar em objetos jurídicos que não lhes pertencem ou que lhes pertencem sem exclusividade, mas à sociedade de modo geral, que vão além das previsões normativas descritas no direito positivo, o que já é algo aceito nas cartilhas de administração de empresas.

A responsabilidade social da empresa é vista como um compromisso da empresa em relação à sociedade e à humanidade em geral e uma forma de prestação de contas do seu desempenho, baseado na apropriação e uso de recursos que originariamente não lhe pertence (MELO NETO; FRÓES, 1999, p. 82).

Como nos atos humanos, qualquer organização, independentemente de tamanho, setor, atividade ou lugar, tem liberdade para se instalar (viver), se desenvolver e prosperar. Porém, tem em contrapartida a obrigação de atuar como co-responsável pelo desenvolvimento e bem-estar dos agentes do seu entorno (KARKOTLI; ARAGÃO, 2004, p. 46).

$\mathrm{Na}$ temática da responsabilidade social empresarial os danos são de natureza social. Assim, a vítima do "dano social" é a sociedade, e a ela deve ser destinada à reparação dos danos por meio de ações preventivas ou reparadoras, onde a indenização pecuniária se converte nos investimentos dessa natureza, por exemplo, uma empresa que emite gases poluentes deve reparar esse dano com investimentos em purificação e controle de emissão, além de punições por parte do Poder Público. Por essa razão, entende-se que a responsabilidade social empresarial pertence aos chamados "Novos Direitos" e assim, sucessivamente, deve ser reconhecida como dever em favor da sociedade, onde ela se pratica nos stakeholders interno e externo, e, conseqüentemente, proporcionar-se-á às empresas uma situação de "maioridade na cidadania empresarial” (KARKOTLI; ARAGÃO, 2004, p. 46-47) em relação ao mercado e à sociedade.

O Estado é insuficiente e incapaz de criar normas para cada questão prática, inclusive jurisprudenciais em face da dinâmica social e do mercado, de tal maneira que o indivíduo e a sociedade não podem ficar a mercê exclusiva de criação de supostos direitos por meio da máquina estatal, levando esses novos direitos se germinam e se legitimam de maneira independente na composição social e no desenvolvimento dos fatos sociais.

Daí, diante desta precariedade normativa expressa, tem-se o problema processual em identificar, materialmente, tanto o direito obrigacional convencional, quanto a prática de ato ilícito na fase de apreciação do juiz em grau de liminar ou até mesmo mediante justificação prévia para a concessão de uma das tutelas de urgência, particularmente em se tratando da tutela específica. 
A proposta de uma solução cabível a esta questão se dá no desenvolvimento e aperfeiçoamento da hermenêutica jurídica, no tocante à análise das fontes, interpretação, integração e aplicação do direito, calcadas nos princípios e fundamentos esparsos e específicos pertinentes à responsabilidade empresarial no âmbito social como deveres e obrigações, dizendo pela linguagem o processo de construção do direito em observância a demonstrações axiológicas, éticas, morais, políticas, econômicas, etc., isto é, o direito como "atividade interpretativa, construindo-se como um sistema compreensivo do comportamento humano" (FERRAZ JR., 1990, p. 48). Vale lembrar que, em questão, a lei nem sempre é fonte primária exclusiva do direito, tendo em vista a sua precariedade normativa nesta seara jurídica e sua falta de evolução precisa diante da dinâmica social e econômica, sob pena de arbitrariedade na aplicação ao caso concreto.

Porém, o sistema jurídico brasileiro, ao que se nota, possui uma maneira amplamente mecanizada de exercer a hermenêutica jurídica, levando a haver incompatibilidades na aplicação do Direito quando o problema versar nos objetos jurídicos pertencentes aos chamados Novos Direitos (difusos, coletivos, sociais e humanos), inclusive no cumprimento da responsabilidade social empresarial. Nisso, esclarece Lênio Luiz Streck (2005) que "não houve ainda, no plano hermenêutico, a devida filtragem em face da emergência de um novo modo de produção de Direito representado pelo Estado Democrático de Direito" (p. 33).

A hermenêutica é um processo de criação e não de mecanização, de tal modo que a aplicação do Direito, principalmente nos dias atuais, não deve ser resumida apenas em textos normativos engessados em leis, códigos e normas ditadas por autoridades competentes, bem como numa visão formalista tradicional da qual se encontra refratária aos aspectos sociais, políticos, econômicos, éticos, etc.

Assim, para o aplicador, identificar precisamente uma obrigação ou a prática de um ato ilícito sem as tradicionais previsões normativas passa a ser um desafio para o direito contemporâneo. Esses direitos materiais, tradicionalmente, são interpretados restritamente por meio das previsões obrigacionais inseridas em leis, normas competentes e por meio de negócios jurídicos desenvolvidos no universo da autonomia privada. A partir do momento em que o direito se perfaz fora dessas esferas formais e privatistas, como é possível ocorrer na teoria dos novos direitos com base na evolução identificada pela sociologia, torna-se complicada pelo aplicador a identificação de um direito obrigacional nesse sentido e, nessa problemática, reflete-se na 
Os desafios da tutela específica em relação aos novos direitos e à responsabilidade social...

efetividade tutelar dos artigos 84 do CDC e 461 do CPC em relação aos direitos existentes no universo da responsabilidade social empresarial.

\section{CONCLUSÃO}

Diante das diferenças entre as duas tutelas analisadas neste trabalho, concluise que a antecipada do artigo 273 do CPC revela o conteúdo a ser dado em procedência da ação com maiores certeza, dimensão e concretude do que a tutela específica, haja vista que esta vincula a diversidade de possíveis situações relacionadas materialmente nas relações obrigacionais.

$\mathrm{Na}$ tutela específica, ao trazer a apreciação do direito material para a sua concessão, em face da atual realidade que o mundo se encontra, calcada nos avanços científicos, tecnológicos, sociais, culturais, econômicos, etc., gerou-se uma imensa dificuldade de concedê-la, principalmente em caráter liminar, levando em conta a dificuldade de ilustração de uma possível relação obrigacional de fazer, de não fazer ou de ato ilícito a ser inibido à luz do mundo e da realidade contemporânea.

A tutela específica, devido à menor exigência instrumental para a sua concessão, se caracteriza com maior excelência sua essência de tutela urgente ao invés da antecipada, tendo em vista sua cognição sumária estar restrita ao objeto obrigacional de fazer, não fazer ou de inibição de ato ilícito.

A tutela específica, à luz da realidade do mundo contemporâneo, jamais deverá ser concedida nos fundamentos da medida cautelar prevista no $§ 7^{\underline{a}}$ do artigo 273 do CPC, pois relações obrigacionais exigem, no seu aspecto material, fortes requisitos de liquidez e certeza, onde a fumaça do bom direito é inadmissível em caso de obrigações de fazer, não fazer ou inibição de atos ilícitos, sob pena de configurar o abuso de direito por parte do autor.

O resultado prático da tutela específica em sua devida concessão é prejudicado na medida da complexidade do instituto material do direito obrigacional à luz da realidade contemporânea dinâmica e assim inviabilizando o conhecimento prévio do juiz, levando em consideração a tradição e a postura refratária de perspectivas privatista e contratualista na aplicação do direito diante do complexo jurisdicional e material brasileiro perante as realidades e necessidades contemporâneas. A insuficiência de substratos jurídico-formais para a identificação de uma relação obrigacional de fazer, não fazer ou de ato ilícito a ser inibido leva a uma maior dificuldade na concessão de tutelas específicas no caso concreto, mesmo ciente de que hoje é tecnicamente impossível disciplinar tais relações por meio de leis, normas e convenções 
capazes de acompanhar em sincronia a complexa dinâmica da sociedade e da economia, principalmente em se tratando dos chamados "Novos Direitos" e em especial ao universo jurídico da responsabilidade social empresarial.

As relações obrigacionais relativas à responsabilidade social empresarial existem e elas são indiscutivelmente reconhecidas por estudiosos pertencentes às mais diversas áreas de conhecimento em questão. Há não somente obrigações de fazer e não fazer como também atos ilícitos a serem inibidos, calcados na teoria da responsabilidade e na sua conseqüente obrigação de reparar os danos de natureza social e o seu reconhecimento vem sendo dado independentemente de leis ou previsões normativas, jurisprudenciais ou convencionais para sua legitimação na sociedade.

Dessa forma, o desenvolvimento, a prática e o aperfeiçoamento da hermenêutica jurídica, no tocante a análise das fontes, interpretação, integração e aplicação do direito é fundamental para a devida adequação e identificação dessas complexas e variadas formas de geração de relações obrigacionais ou de ilustração de atos ilícitos a serem inibidos no contexto da responsabilidade social empresarial, desde que essa visão hermenêutica se desprenda aos moldes tradicionais exclusivamente formalistas, legalista e de perspectivas privatista e contratualista, devendo compartilhar com aspectos sociais, políticos, econômicos, éticos, etc.

Diante de tais situações problemáticas, identificar as relações obrigacionais de fazer, não fazer ou de atos ilícitos a serem inibidos sem as exclusivas régias normativistas no pedido de tutela específica passa a ser um desafio para a doutrina e para os operadores do direito em se tratando dos chamados "Novos Direitos", especialmente na complexidade do universo específico da responsabilidade social empresarial.

\section{REFERÊNCIAS}

BOBBIO, Norberto. A Era dos Direitos. 9. ed. Rio de Janeiro: Campus, 1992.

CARNELUTTI, Francesco. Instituições do processo civil. Campinas: Servanda, 1999. v. 1.

CINTRA, Antonio Carlos de Araújo; GRINOVER, Ada Pellegrini; DINAMARCO, Cândido Rangel. Teoria geral do processo. 22. ed. São Paulo: Malheiros, 2006.

INAMARCO, Cândido Rangel. A reforma do código de processo civil. 3. ed. São Paulo: Malheiros, 1996. 
Os desafios da tutela específica em relação aos novos direitos e à responsabilidade social...

. Fundamentos do processo civil moderno. 5. ed. São Paulo: Malheiros, 2002. Tomo I.

. Instituições de direito processual civil. 2. ed. São Paulo: Malheiros, 2002. v. 3.

DINIZ, Maria Helena. Curso de direito civil brasileiro. 21. ed. São Paulo: Saraiva, 2006. v. 2.

FERRAZ JR. Tércio Sampaio. A ciência do direito. 2. ed. São Paulo: Atlas, 1990.

FREIRE, Reis. Principais inovações no direito processual civil brasileiro. Rio de Janeiro: Forense Universitária, 1996.

GOMES, Orlando. Obrigações. 13. ed. Rio de Janeiro: Forense, 2000.

KARKOTLI, Gislon; ARAGÃO, Sueli Duarte. Responsabilidade social: uma contribuição à gestão transformadora das organizações. Petrópolis: Vozes, 2004.

MARINONI, Luiz Guilherme. Tutela específica: (arts. 461, CPC e 84, CDC). São Paulo: Editora Revista dos Tribunais, 2000.

. Tutela inibitoria: individual e coletiva. 2. ed. São Paulo: Ed. Revista dos Tribunais, 2000.

MARINONI, Luiz Guilherme; ARENHART, Sérgio Cruz. Curso de processo civil. 6. ed. São Paulo: Ed. Revista dos Tribunais, 2007. v. 2.

MARQUES, José Frederico. Manual de direito processual civil. Campinas: Millennium, 2000. v. 2, pt. 1.

MELO NETO, Francisco Paulo de; FRÓES, César. Responsabilidade social \& cidadania empresarial: administração do terceiro setor. Rio de Janeiro: Quatilymark, 1999.

MIRANDA, Pontes de. Tratado das ações. Campinas: Bookseller, 1998. t. 1, 6. NERY JÚNIOR, Nelson. Atualidades sobre o processo civil: a reforma do código de processo civil brasileiro de 1994 e de 1995. São Paulo: Ed. Revista dos Tribunais, 1996.

NERY JUNIOR, Nelson; NERY, Rosa Maria Andrade. Código de processo civil comentado e legislação processual civil extravagante em vigor. 5. ed. São Paulo: Ed. Revista dos Tribunais, 2001. 
PEREIRA, Caio Mário da Silva. Instituições de direito civil. 20. ed. Rio de Janeiro: Forense, 2003. v. 2.

SILVA, Ovídio Araújo Baptista da. Curso de processo civil: processo de conhecimento. 5. ed. São Paulo: Ed. Revista dos Tribunais, 2000. v. 1.

SIQUEIRA, Mirian Cândida de Oliveira. Responsabilidade social empresarial: filantropia ou idealismo? 2002. 212f. Dissertação (Mestrado em Serviço Social)

- Faculdade de História, Direito e Serviço Social - UNESP, Franca, 2002.

STRECK, Lenio Luiz. Hermenêutica jurídica em crise: uma exploração hermenêutica da construção do direito. Porto Alegre: Livraria do Advogado, 2005.

WATANABE, Kazuo. Da cognição no processo civil. Campinas: Bookseller, 2000.

VENOSA, Sílvio de Salvo. Direito civil: teoria geral das obrigações e teoria geral dos contratos. 3. ed. São Paulo: Atlas, 2003. 